\title{
Piperaceae do Parque Nacional do Viruá, Caracaraí, Roraima, Brasil
}

\author{
Piperaceae of the Parque Nacional do Viruá, Caracaraí, Roraima, Brazil
}

Aline Melo ${ }^{2,4}$, Elsie Franklin Guimarães ${ }^{3} \&$ Marccus Alves $^{2}$

\begin{abstract}
Resumo
Piperaceae possui cinco gêneros, aproximadamente 3.600 espécies com distribuição pantropical, e no Brasil a família está representada por cerca de 450 táxons. Portanto, o objetivo desta pesquisa foi realizar o estudo taxonômico das espécies que ocorrem no Parque Nacional do Viruá, estado de Roraima. As coletas foram realizadas entre setembro de 2011 e agosto de 2012, além de levantamento nos herbários. Foram encontrados 16 táxons, sendo 12 do gênero Piper L. e quatro de Peperomia Ruiz \& Pav. Onze táxons são novos registros para o estado, além de um novo registro para o Brasil. A maioria das espécies foi coletada em áreas de Floresta de Terras Baixas, além de Florestas de Várzea.
\end{abstract}

Palavras-chave: Escudo das Guianas, Floresta Amazônica, novos registros, Piper.

\begin{abstract}
Piperaceae comprises five genera, approximately 3.600 species with a pantropical distribution, and in Brazil this family is represented by about 450 taxa. Therefore, the aim of this research was do the taxonomic treatment of species that occur in Parque Nacional do Viruá, state of Roraima. Field trips were conducted between September 2011 and August 2012, and vouchers from herbaria were also analyzed. We found 16 taxa, 12 of the genus Piper L. and four of Peperomia Ruiz \& Pav. Eleven taxa are new records for the state, and one is a new record for Brazil. Most species were collected in the lowlands forests, but some were found in floodplain forests.
\end{abstract}

Key words: Amazonian forest, Guayana Shield, new records, Piper.

\section{Introdução}

Piperaceae possui cinco gêneros (Manekia Trel., Peperomia Ruiz \& Pav., Piper L., Verhuellia Miq. e Zippelia Blume) e cerca de 3.600 espécies com distribuição pantropical (Tebbs 1993; QuijanoAbril et al. 2006; Wanke et al. 2006; Samain et al. 2008). Com exceção do gênero monotípico Zippelia, que ocorre na Ásia tropical, todos os demais gêneros estão bem representados na região Neotropical (Tebbs 1993; Suwanphakdee \& Chantaranothai 2009). No Brasil Piperaceae está representado por aproximadamente 450 táxons, distribuídos em três gêneros e com maior diversidade na Mata Atlântica e Amazônia, com cerca de 280 e 230 táxons respectivamente (Guimarães et al. 2013).

Os representantes da família podem ser ervas epífitas, terrícolas ou rupícolas, hemiepífitas, trepadeiras, arbustos eretos ou escandentes, ou pequenas árvores. As folhas são simples, alternas, opostas ou verticiladas, de margem inteira e geralmente possuem odor característico. As inflorescências são em espiga ou racemo, solitárias ou não, axilares, terminais ou opositifolias. As flores são numerosas, diminutas, bissexuadas ou unissexuadas, aclamídeas e cada uma subentendida por uma bráctea floral. Cada flor é formada por dois a seis estames livres com anteras rimosas, o gineceu apresenta de um a quatro estigmas, séssil ou provido de estilete, ovário súpero, séssil ou pedicelado, unilocular e com um óvulo basal. Os frutos são drupas (Yuncker 1972).

Sem dúvida o maior trabalho de Piperaceae para o Brasil foi realizado por Yuncker em "The Piperaceae of Brazil" (1972, 1973, 1974), com o

\footnotetext{
${ }^{1}$ Parte da dissertação de Mestrado da primeira autora.

${ }^{2}$ Universidade Federal de Pernambuco, Centro de Ciências Biológicas, Depto. Botânica, Lab. Morfo-Taxonomia Vegetal, Av. Prof. Moraes Rego s/n, Cidade Universitária, 50670-901, Recife, PE, Brasil.

${ }^{3}$ Instituto de Pesquisas Jardim Botânico do Rio de Janeiro, R. Pacheco Leão 915, 22460-030, Rio de Janeiro, RJ, Brasil.

${ }^{4}$ Autor para correspondência: aline_vmelo@yahoo.com.br
} 
tratamento taxonômico de cerca de 500 táxons, chaves de identificação e fotografias de exsicatas. Posteriormente, várias floras locais e estaduais no país foram realizadas, porém com maior número na região Sudeste do país (Ichaso et al. 1977; Carvalho-Okano \& Alves 1998; Guimarães 1999; Guimarães \& Monteiro 2006; Medeiros \& Guimarães 2007; Bardelli et al. 2008; Monteiro \& Guimarães 2008, 2009; Carvalho-Silva \& Guimarães 2009; Guimarães \& Carvalho-Silva 2012), e alguns pontuais para a região Sul (Guimarães et al. 1984; Guimarães \& Valente 2001), Centro-oeste (Carvalho-Silva \& Cavalcanti 2002; Guimarães et al. 2007) e Nordeste (CallejasPosada 1995; Guimarães \& Giordano 2004; Melo et al. 2013). Já para a região Norte do Brasil, além de Guimarães et al. (2007) que envolve o estado de Tocantins, há apenas uma listagem e um guia (Costa \& Callejas-Posada 1999; Callejas-Posada 2008).

Com isso, o presente trabalho tem como objetivo geral registrar as espécies de Piperaceae ocorrentes no Parque Nacional do Viruá, localizado no estado de Roraima, através de descrições, chave de identificação, ilustrações, comentários taxonômicos e de distribuição geográfica dos táxons encontrados.

\section{Materiais e Métodos}

O Parque Nacional (PARNA) do Viruá (1²9'26"N e 61\%00'09'O) foi criado em 1998 (Brasil 1998) e situa-se no município de Caracaraí a aproximadamente $140 \mathrm{~km}$ de Boa Vista, fazendo limites ao norte com Estação Ecológica de Caracaraí, a oeste com o Rio Branco, a leste com o traçado inicial da BR 174 (conhecido como Estrada Perdida) e ao sul com o Rio Anauá. Possui 227.011 ha, composto por um mosaico de fitofisionomias, como Florestas Ombrófilas Abertas de Terras Baixas, Submontanas e Aluviais (incluindo várzeas e igapós), além de Campinaranas Florestadas, Arborizadas e Gramíneo-lenhosas, sensu IBGE (2012). Possui clima Am (Tropical chuvoso), com pluviosidade anual de aproximadamente $2.000 \mathrm{~mm}$, e altitude entre 60 e 360 m (Schaefer et al. 2009).
Expedições a campo foram realizadas de setembro de 2011 a agosto de 2012, com aproximadamente 30 dias de esforço amostral, e o material foi tratado de acordo com as técnicas usuais em botânica (Mori et al. 1989). As amostras foram depositadas no Herbário INPA e as duplicatas enviadas para o RB e UFP (acrônimos segundo Thiers continously updated). A pesquisa contemplou o estudo das amostras de acervos considerados estratégicos nesta pesquisa: EAFM, HB, HUAM (Herbário da Universidade Federal do Amazonas), IAN, INPA, MG, MIRR, R, RB e UFRR (Herbário da Universidade Federal de Roraima). As identificações foram realizadas com base em bibliografias especializadas (Trelease \& Yuncker 1950; Yuncker 1972, 1973, 1974; Görtsvan Rijn 2002; Steyermark \& Callejas-Posada 2003) e consulta aos protólogos.

As descrições dos táxons foram baseadas nos espécimes coletados na área de estudo, a exceção de alguns, que necessitaram de material adicional proveniente de outras localidades da Amazônia (neste caso indicados). A terminologia adotada para morfologia, padrão de venação e pilosidade da folha seguiu Hickey (1974) e Harris \& Harris (2001).

\section{Resultados e Discussão}

No PARNA Viruá foram reconhecidos 16 táxons de Piperaceae, distribuídos nos gêneros Peperomia (4 espécies) e Piper (12 táxons). Com base em Guimarães et al. (2013) e Yuncker (1972, 1973, 1974), são apresentados 11 novos registros para o estado de Roraima e um para o Brasil. Sobre a distribuição no Brasil dos táxons encontrados, nove deles estão presentes apenas na Amazônia, quatro ocorrem na Amazônia e Mata Atlântica, e o restante além de estarem presentes nesses dois domínios, também ocorrem no Cerrado. Apesar das diversas fitofisionomias encontradas na área de estudo, a maioria dos táxons do gênero Piper foi encontrado em áreas de Floresta de Terras Baixas, e os de Peperomia em Floresta Aluvial de Várzea (Tab. 1). 
Tabela 1 - Táxons encontrados no Parque Nacional do Viruá com suas respectivas fitofisionomias de ocorrência na área de estudo e domínios no Brasil. FV=Floresta de Várzea; FTB=Floresta de Terras Baixas; $\mathrm{CF}=$ Campinarana Florestada; $\mathrm{AM}=$ Amazônia; $\mathrm{CE}=$ Cerrado; $\mathrm{MA}=$ Mata Atlântica. *Nova ocorrência em Roraima; **Nova ocorrência no Brasil.

Table 1 - Taxa found in Parque Nacional do Viruá with vegetation types in the study area and dominions of Brazil. FV= Fodplain forest; FTB= Lowland Forest; $\mathrm{CF}=$ Forested Campinarana; $\mathrm{AM}=$ Amazon Forest; $\mathrm{CE}=$ Cerrado; $\mathrm{MA}=$ Atlantic Rainforest. *New record of Roraima; **New record to Brazil.

\begin{tabular}{lcc}
\hline Táxon & $\begin{array}{c}\text { Fitofisionomia no } \\
\text { PARNA Viruá }\end{array}$ & $\begin{array}{c}\text { Domínio de ocorrência } \\
\text { no Brasil }\end{array}$ \\
\hline Peperomia elongata Kunth. & FV & AM, CE e MA \\
Peperomia glabella (Sw.) A. Dietr.* & FV & AM e MA \\
Peperomia quadrangularis (J.V. Thomps.) A. Dietr. & FV e CF & AM \\
Peperomia rotundifolia (L.) Kunth.* & FV & AM e MA \\
Piper aleyreanum C. DC.* & FTB & AM \\
Piper arboreum var. hirtellum Yunck.* & FTB e MA \\
Piper bartlingianum (Miq.) C. DC. & FTB & AM e MA \\
Piper consanguineum (Kunth) Steud.* & FTB & AM \\
Piper cyrtopodon (Miq.) C. DC.* & FTB & AM \\
Piper demeraranum (Miq.) C. DC. & FTB & AM \\
Piper glabrescens (Miq.) C. DC.** & FTB & AM \\
Piper goeldii C. DC.* & CF & AM \\
Piper hispidum Sw. & FTB & AM, CE e MA \\
Piper hostmannianum (Miq.) C. DC.* & FTB e CF & AM e MA \\
Piper plurinervosum Yunck.* & FTB & FV \\
Piper schwackei C. DC.* & AM e MA \\
\hline
\end{tabular}

\section{Chave de identificação para os táxons de Piperaceae do Parque Nacional do Viruá}

1. Ervas epífitas com ramos prostrados e eretos; estames-2, estigma-1 1. Peperomia

2. Folhas opostas, coriáceas quando secas 1.3. Peperomia quadrangularis

2'. Folhas alternas, membranáceas quando secas.

3. Planta coberta por glândulas negras (ramos, pecíolos, folhas, pedúnculo, raque, brácteas e frutos) 1.2. Peperomia glabella

3'. Planta não coberta por glândulas negras.

4. Ervas prostradas com até $5 \mathrm{~cm}$ de alt.; folhas $0,4-1,4 \mathrm{~cm}$ compr., orbiculares, obovadas ou romboideas 1.4. Peperomia rotundifolia

4'. Ervas eretas com mais de $15 \mathrm{~cm}$ de alt.; folhas (2)4-8 cm compr., elípticas a lanceoladas 1.1. Peperomia elongata

1'. Arbustos eretos ou escandentes, ou hemiepífitas; estames (2)3-4, estigmas 3-4 2. Piper

5. Folhas de base fortemente assimétrica com diferença $\leq 0,8 \mathrm{~cm}$ entre os lobos

2. Piper arboreum var. hirtellum

5'. Folhas com base simétrica ou assimétrica, quando assimétrica com diferença $\geq 0,6 \mathrm{~cm}$ entre os lobos.

6. Folhas com ambas as faces glabras a glabrescentes.

7. Pecíolo canaliculado (não alado, nem sulcado); espigas 5-10,5 cm compr.; estigmas-4; drupas elipsoides e não comprimidas lateralmente 2.3. Piper bartlingianum

7'. Pecíolo sulcado ao menos na base; espigas 1,5-3 cm compr.; estigmas-3; drupas tetragonais e comprimidas lateralmente 2.7. Piper glabrescens 
6'. Folhas pilosas, hispidulosas, hirsutas ou estrigosas ao menos ao longo das nervuras da face abaxial.

8. Face adaxial da folha híspida e áspera ao toque 2.9. Piper hispidum

8'. Face adaxial da folha glabra e lisa ao toque.

9. Folhas com um dos lobos da base auriculado, nervuras da face abaxial com tricomas de diferentes comprimentos 2.6. Piper demeraranum

9'. Folhas com nenhum dos lobos da base auriculado, nervuras da face abaxial com tricomas de um único comprimento.

10. Hemiepífitas ou arbustos escandentes.

11. Hemiepífitas; folhas oblongas a elípticas; espigas 0,5-2,7 cm compr.; estilete desenvolvido 2.8. Piper goeldii

11'. Arbustos escandentes; folhas lanceoladas; espigas (4)6-10 cm compr.; estigmas sésseis 2.12. Piper schwackei

10'. Arbustos eretos.

12. Espigas pendentes

2.1. Piper aleyreanum

12'. Espigas eretas

13. Face abaxial da folha vilosa; estames-3

2.11. Piper plurinervosum

13'. Face abaxial da folha glabra ou glabrescente a pilosa; estames 2 ou 4.

14. Drupas sem depressão no ápice e não comprimidas lateralmente

2.5. Piper cyrtopodon

14'. Drupas com depressão no ápice e comprimidas lateralmente.

15. Espigas 1-3 cm compr., apiculadas; estames-2; estilete desenvolvido de até $0,5 \mathrm{~mm}$ compr.

2.4. Piper consanguineum

15'. Espigas acima de $5 \mathrm{~cm}$ compr., não apiculadas; estames-4; estigmas sésseis 2.10. Piper hostmannianum

1. Peperomia Ruiz \& Pav., Fl. Peruv. Prodr. 6, pl. 2. 1794.

Ervas epífitas com ramos eretos ou prostrados. Folhas crassas quando frescas e membranáceas ou coriáceas quando secas, alternas ou opostas, padrão de venação acródromo ou pinado-eucamptódromo; pecíolo cilíndrico, canaliculado, anguloso ou sulcado, ciliado ou não ciliado. Inflorescência em espiga, solitária ou agrupadas em até 3 , ereta ou arqueada, axilar ou terminal; raque glabra. Flores congestas ou laxas; estames-2; estigma-1, apical ou subapical, séssil; bráctea floral orbicular a oval, peltada, não ciliada, glabra. Drupas globoides ou elipsoides, sésseis, pseudocúpula ausente.

Gênero pantropical com cerca de 1.600 espécies (Wanke et al. 2006). No Brasil está presente em quase todos os estados, sendo 57 espécies citadas para a Amazônia, das quais apenas 12 são listadas como ocorrentes no estado de Roraima (Guimarães et al. 2013). No PARNA do Viruá foram encontradas quatro espécies, sendo duas novos registros para o estado. Habitam locais de Floresta Aluvial de Várzea, e uma delas também foi encontrada em Campinarana Florestada.
1.1 Peperomia elongata Kunth in H.B.K., Nov. Gen. Sp. (quarto ed.) 1: 62.1815. Fig. 1a-b Ervas epífitas até $30 \mathrm{~cm}$ alt. Ramos eretos, cilíndricos, glabros ou esparsamente pilosos. Folhas $(2-) 4-8 \times(0,7-) 1,5-2,8 \mathrm{~cm}$, alternas, membranáceas quando secas, glabras, elípticas a lanceoladas, base cuneada, obtusa a arredondada, ápice agudo, atenuado ou raro emarginado,ciliado, margem não ciliada a esparsamente ciliada; padrão de venação pinada (ou raro acródroma), 2-4 pares de nervuras secundárias, com 1-2 pares saindo da base e até 2 pares surgindo até próximo à porção mediana da folha; pecíolo $0,5-2,5 \mathrm{~cm}$ compr., levemente sulcado, ciliado na margem do sulco. Espigas 6,5-15 ×0,2-0,3 cm, solitárias, arqueadas, terminais, bracteadas; brácteas-2, 5-7 × 0,5-1 mm, alternas, lineares a lanceoladas, ápice atenuado; pedúnculo 0,5-1,3 cm compr., glabro. Flores congestas; estigma apical; bráctea floral orbicular. Drupas $0,8-1,2 \times 0,5-1 \mathrm{~mm}$, elipsoides, ápice oblíquo, papilosas, glabras.

Material examinado: Rio Branco, Igarapé do Aliança, 28.XI.2011, fl., E. Pessoa \& S. Vasconcelos 829 (INPA, UFP); Rio Anauá, 23.VIII.2012, fl. e fr., A. Melo et al. 1021 (INPA, UFP). 


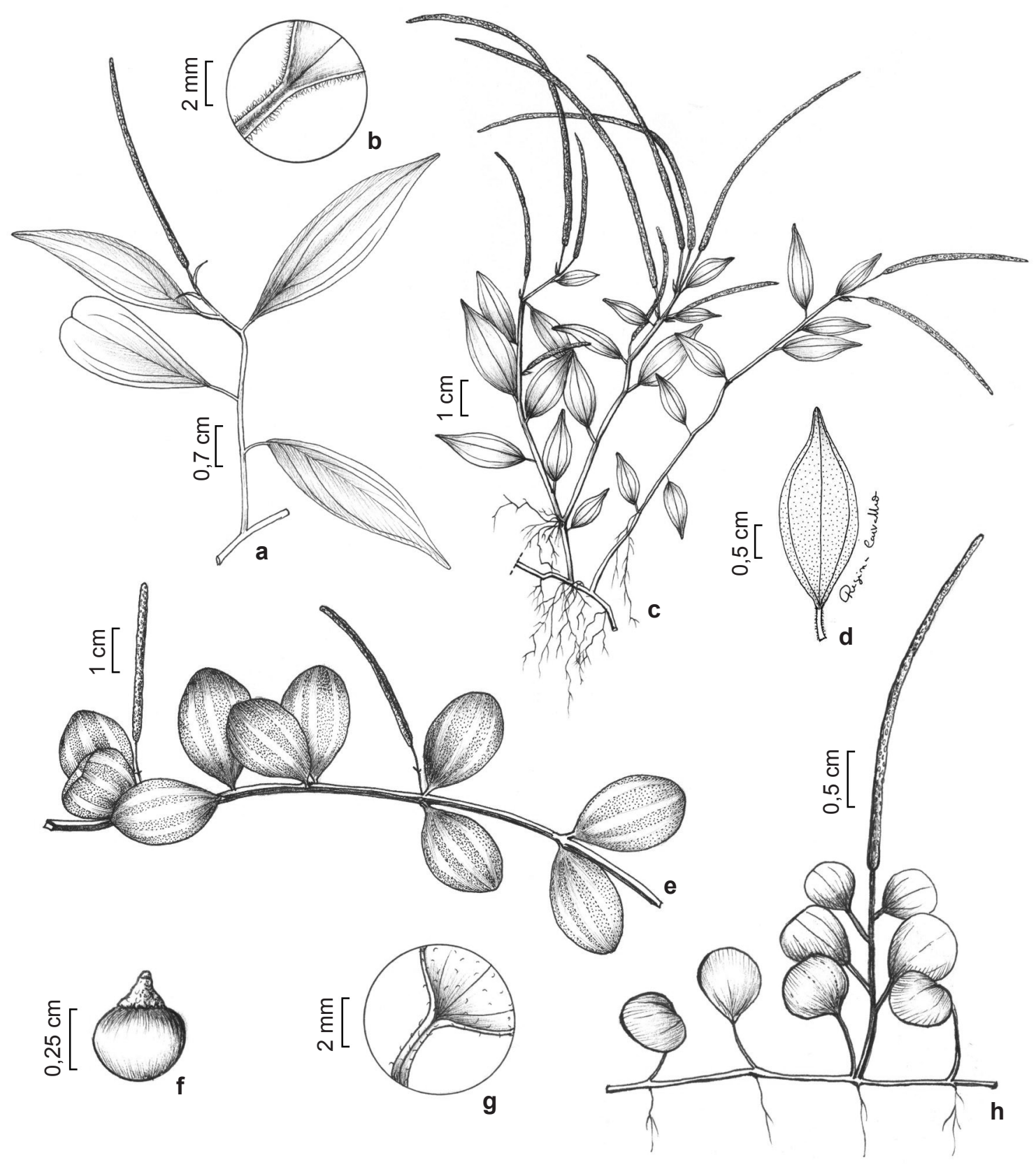

Figura 1 - a-b. Peperomia elongata Kunth. - a. ramo fértil (E. Pessoa \& S. Vasconcelos 829); b. detalhe do pecíolo e base da folha (E. Pessoa \& S. Vasconcelos 829). c-d. Peperomia glabella (Sw.) A. Dietr. - c. hábito (E. Pessoa \& $S$. Vasconcelos 833); d. folha evidenciando as glândulas negras e o pecíolo ciliado (E. Pessoa \& S. Vasconcelos 833). e-f. Peperomia quadrangularis (J.V. Thomps.) A. Dietr. (A. Melo et al. 908) - e. ramo fértil; f. fruto individualizado. g-h. Peperomia rotundifolia (L.) Kunth. (E. Pessoa \& S. Vasconcelos 852) - g. detalhe do pecíolo e base da folha; h. hábito.

Figure 1 - a-b. Peperomia elongata Kunth. - a. fertile stem (E. Pessoa \& S. Vasconcelos 829); b. detail of the petiole and leaf base (E. Pessoa \& S. Vasconcelos 829). c-d. Peperomia glabella (Sw.) A. Dietr. - c. habit (E. Pessoa \& S. Vasconcelos 833); d. leaf showing the black dots and ciliate petiole (E. Pessoa \& S. Vasconcelos 833). e-f. Peperomia quadrangularis (J.V. Thomps.) A. Dietr. (A. Melo et al. 908) - e. fertile stem; f. fruit individualized. g-h. Peperomia rotundifolia (L.) Kunth. (E. Pessoa \& S. Vasconcelos 852) - g. detail of the petiole and base of leaf; h. habit. 
Distribuída pela Colômbia, Venezuela, Guiana, Suriname e Guiana Francesa (Trelease \& Yuncker 1950; Steyermark \& Callejas-Posada 2003), e no Brasil está presente na Amazônia, Cerrado e Mata Atlântica (Guimarães et al. 2013). Segundo Steyermark \& Callejas-Posada (2003) a espécie possui três variedades que são diferenciadas pela forma, tamanho e pilosidade de suas folhas. Entretanto, optou-se por não utilizar nenhuma delas, uma vez que essas características não foram distintas nas amostras provenientes de outras áreas do estado. No PARNA foi encontrada apenas em locais de Floresta de Várzea e separa-se das demais espécies do gênero por possuir maior porte (até $30 \mathrm{~cm}$ alt.), folhas de ápice ciliado, e frutos elipsoides. Segundo Di Stasi et al. (2002), Peperomia elongata é usada por índios contra diarreia e fortes dores estomacais.

\subsection{Peperomia glabella (Sw.) A. Dietr., Sp. Pl. (ed.} 6) 1: 156. 1831.

Fig. 1c-d

Ervas epífitas até $25 \mathrm{~cm}$ alt., glândulas negras presentes em toda a planta. Ramos eretos e prostrados, cilíndricos, glabros ou esparsamente pilosos. Folhas (1)1,5-7,4 × $(0,4) 1-3 \mathrm{~cm}$, alternas, membranáceas quando secas, glabras, elípticas a ovadas, base cuneada a obtusa, ápice agudo a atenuado ou raro emarginado, ciliado, margem não ciliada; padrão de venação pinada, geralmente com 1-2 pares de nervuras secundárias saindo da base, e outros dois pares podendo sair ao longo da nervura principal; pecíolo 0,2-1 cm compr., canaliculado, glabro, ciliado e prolongando-se até a base da folha. Espigas (4)7-12,5 × 0,05-0,08 cm compr., solitárias ou agrupadas em até três, arqueadas, terminais ou axilares, bracteadas; bráctea-1, 2-5 x 0,3-0,5 mm, elípticas a lanceoladas, ápice atenuado a agudo; pedúnculo 0,5-1,3 cm compr., glabro. Flores laxas; estigma subapical; bráctea floral orbicular a elíptica. Drupas 0,5-0,8 × 0,5-0,8 mm, globoides, glabras.

Material examinado: Rio Branco, Igarapé do Aliança, 28.XI.2011, fl., E. Pessoa \& S. Vasconcelos 833 (INPA, UFP); Rio Anauá, 28.XI.2011, fl., E. Pessoa \& S. Vasconcelos 854 (INPA, UFP); 24.VIII.2012, fl. e fr., A. Melo et al. 1033 (INPA, UFP).

Distribuída pela América Central, Ilhas Caribenhas e América do Sul (Steyermark \& Callejas-Posada 2003). No Brasil está citada para a Amazônia (Amapá, Amazonas, Pará e Acre) e Mata Atlântica, do Ceará ao Paraná (Guimarães et al. 2013), sendo aqui registrada para Roraima. Segundo Yuncker (1974) e Steyermark \& CallejasPosada (2003), a espécie possui duas variedades: $P$. glabella var. glabella e P. glabella var. nervulosa (C. DC.) Yunck., que se diferenciam principalmente pelo tamanho de suas folhas. Entretanto, nos indivíduos observados na área de estudo, os caracteres empregados para separação dessas variedades não foi consistente. $\mathrm{Na}$ área de estudo foi encontrada em Florestas de Várzea e diferenciase dos demais táxons da família principalmente pelas glândulas negras presentes por toda a planta.

1.3 Peperomia quadrangularis (J.V. Thomps.) A. Dietr., Sp. Pl. (ed. 6) 1: 169. 1831. Fig. 1e-f

Ervas epífitas até $10 \mathrm{~cm}$ alt. Ramos prostrados, angulosos quando secos, glabros ou esparsamente hispidulosos. Folhas $2-3,6 \times 0,8-2,4 \mathrm{~cm}$, opostas, coriáceas quando secas, glabras ou esparsamente hispidulosas, obovadas, romboidais ou raro orbiculares, base obtusa a arredondada ou raro cuneada, ápice arredondado a obtuso e não ciliado, margem não ciliada ou esparso ciliada; padrão de venação acródroma, 3-nervada; pecíolo 0,2-0,5 cm compr., anguloso quando desidratado, hispiduloso. Espigas 1,3-4 × 0,05-0,1 cm compr., solitárias, eretas, axilares, bracteadas; brácteas-2, 1-2,5 $\times$ 0,3-0,5 mm, opostas, lineares a elípticas, ápice obtuso a arredondado; pedúnculo até $4 \mathrm{~cm}$ compr., hispiduloso. Flores laxas; estigma séssil, apical; bráctea floral orbicular. Drupas $0,5-0,7 \times 0,5-0,7$ $\mathrm{mm}$, globoides, ápice levemente oblíquo, glabras. Material selecionado: Margem do Rio Barauana, 22.IX.2011, fr., A. Melo et al. 908 (INPA, RB, UFP); 31.X.2011, fl., A. Melo et al. 934 (INPA); Margem do Rio Anauá, 24.VIII.2012, fl., A. Melo et al. 1030 (INPA, UFP).

Distribuída nas Ilhas Caribenhas, Panamá, Colômbia, Venezuela, Guiana, Suriname (Trelease \& Yuncker 1950), e no Brasil limita-se a Amazônia, nos estados do Amazonas, Pará e Roraima (Guimarães et al. 2013). No Viruá ela foi observada em locais de Floresta de Várzea e Campinarana Florestada, considerada uma das espécies mais comuns de Peperomia do PARNA e geralmente encontrada junto a Peperomia rotundifolia. Pode ser reconhecida por possuir ramos angulosos quando desidratados, além do padrão de venação acródromo-trinervado.

1.4 Peperomia rotundifolia (L.) Kunth in H.B.K., Nov. Gen. Sp. (quarto ed.) 1: 65. 1815. Fig. 1g-h Ervas epífitas até $5 \mathrm{~cm}$ alt. Ramos prostrados, cilíndricos, glabros ou esparsamente hispidulosos. Folhas 0,4-1,4×0,4-1,1 cm, alternas, membranáceas quando secas, glabras ou pilosas, glândulas marrons presentes ou não, orbiculares 
a romboideas, base arredondada a obtusa ou rara cuneada, ápice arredondado à levemente obtuso ou raro levemente emarginado, ciliada ou não ciliada, margem não ciliada ou esparso ciliada, padrão de venação acródromo, 3-5 nervada e inconspícua; pecíolo 2-5 mm compr., cilíndrico, glabro ou hispiduloso. Espigas 3-7 × 0,05-0,08 cm compr., solitárias, eretas, terminais; brácteas não observadas; pedúnculo 0,5-0,8 cm compr., glabro. Flores laxas; estigma séssil, apical; bráctea floral orbicular. Drupas 0,3-0,5 × 0,3-0,5 mm, globoides, papilosas, glabras.

Material selecionado: Margem do Rio Barauana, 22.IX.2011, fl., A. Melo et al. 909 (INPA, RB, UFP); Margem do Rio Anauá, 29.XI.2011, fl., E. Pessoa \& S. Vasconcelos 852 (INPA, RB, UFP); 23.VIII.2012, fl., $A$. Melo et al. 1023 (INPA, UFP).

Distribuída pela América tropical (Trelease \& Yuncker 1950). No Brasil está presente na Amazônia, nos estados do Amazonas, Pará e Acre, e Mata Atlântica de Pernambuco ao Rio Grande do Sul (Guimarães et al. 2013), sendo aqui registrada para Roraima. No PARNA também é considerada uma espécie comum de Peperomia, encontrada em locais de Floresta de Várzea e pode ser reconhecida por ser uma erva delicada de folhas pequenas (0,4-1,4 cm compr.), e orbiculares a romboidais. Segundo Di Stasi et al. (2002) a espécie é utilizada na Mata Atlântica como sedativo e contra dores de estômago, gastrite e gripe.

\section{Piper L., Sp. Pl. 1: 28-30. 1753.}

Arbustos eretos ou escandentes, ou hemiepífitas. Ramos com nós proeminentes. Folhas alternas, base simétrica ou assimétrica, por vezes com glândulas negras ou marrons, margem não ciliada ou esparsamente ciliada; padrão de venação pinada, eucamptódroma ou broquidódroma; pecíolo cilíndrico, canaliculado, sulcado na base ou alado por toda sua extensão. Inflorescência em espiga, opositifolia, solitária, ereta ou pendente; raque glabra ou fimbriada. Flores congestas; estames (2)3-4; estigmas 3-4, sésseis ou com estilete desenvolvido; bráctea floral cuculada, triangular, ou orbicular, peltada, ciliada, fimbriada, ciliada ou não ciliada. Drupas globoides, piramidais ou tetragonais, geralmente comprimidas lateralmente.

Gênero pantropical com cerca de 2.000 espécies (Quijano-Abril et al. 2006), sendo amplamente distribuído no Brasil com ocorrência de aproximadamente 300 táxons (Guimarães et al. 2013). Na Amazônia estão registradas aproximadamente 170 espécies, dos quais 17 ocorrem em Roraima (Guimarães et al. 2013). Na área de estudo foram encontrados 12 táxons, sendo nove deles novos registros para o estado. Em geral ocorrem em locais de Floresta de Terras Baixas, mas um deles foi encontrado em Floresta Aluvial de Várzea, e outro em Campinarana Florestada.

2.1 Piper aleyreanum C. DC., Notizbl. Bot. Gart. Berlin-Dahlem 6: 448. $1917 . \quad$ Fig 2a-c

Arbustos eretos 1-1,5 m alt., glândulas marrons presentes. Ramos esparso pilosos e ramos mais jovens pilosos ou estrigosos. Folhas 7-17 × 2,5-7,9 cm, elípticas, oblanceoladas a oblongas, base assimétrica, diferença até $0,6 \mathrm{~cm}$ entre os lobos, lobo inferior arredondado, lobo superior cuneado, ápice agudo, atenuado ou raro arredondado, margem ciliada; face adaxial glabra ou glabrescente; face abaxial esparso pilosa, nervuras esparsamente pilosas ou estrigosas, tricomas de um único tamanho; padrão de venação eucamptódromo, nervuras secundárias 3-4 pares dispostas até próximo a porção mediana da nervura principal; pecíolo 0,3-1,1 cm compr., sulcado, piloso. Espigas 1,5-3,5 × 0,4-0,45 cm, pendentes, apiculadas; pedúnculo 0,3-1 cm compr., piloso; raque fimbriada. Flor estames-2; estigmas-3, estilete inconspícuo; bráctea floral triangular, fimbriada, fimbrias por vezes mais concentradas na margem superior. Drupas 2-4 x 1,5-3 cm, piramidais a tetragonais, comprimidas lateralmente, ápice com depressão, glandulares, pulverulentas.

Material examinado: Trilha de acesso à Grade do PPBio, 10.X.2011, fl., A. Melo \& E. Pessoa 922 (INPA, UFP); 19.VIII.2012, fl. e fr., A. Melo et al. 981 (INPA, UFP).

Considerada endêmica da Amazônia Brasileira, com registro anterior para os estados do Amapá, Amazonas, Acre e Rondônia (Guimarães et al. 2013), aqui está sendo registrada em Roraima. No PARNA foi encontrada apenas em Floresta de Terras Baixas e diferencia-se das demais espécies do gênero por possuir folhas com nervuras da face abaxial, ramos e pecíolos estrigosos ou pilosos, além de ser a única espécie de Piper encontrada na área com espigas pendentes.

2.2 Piper arboreum var. hirtellum Yunck., Ann. Missouri Bot. Gard. 37(1): 64. 1950. Fig. 2d-f

Arbustos eretos 2-3 m alt. Ramos esparso pilosos a densamente hirsutos. Folhas (15)16,5$24(29,2) \times 5,5-10(12,1) \mathrm{cm}$, elípticas a ovadas, 


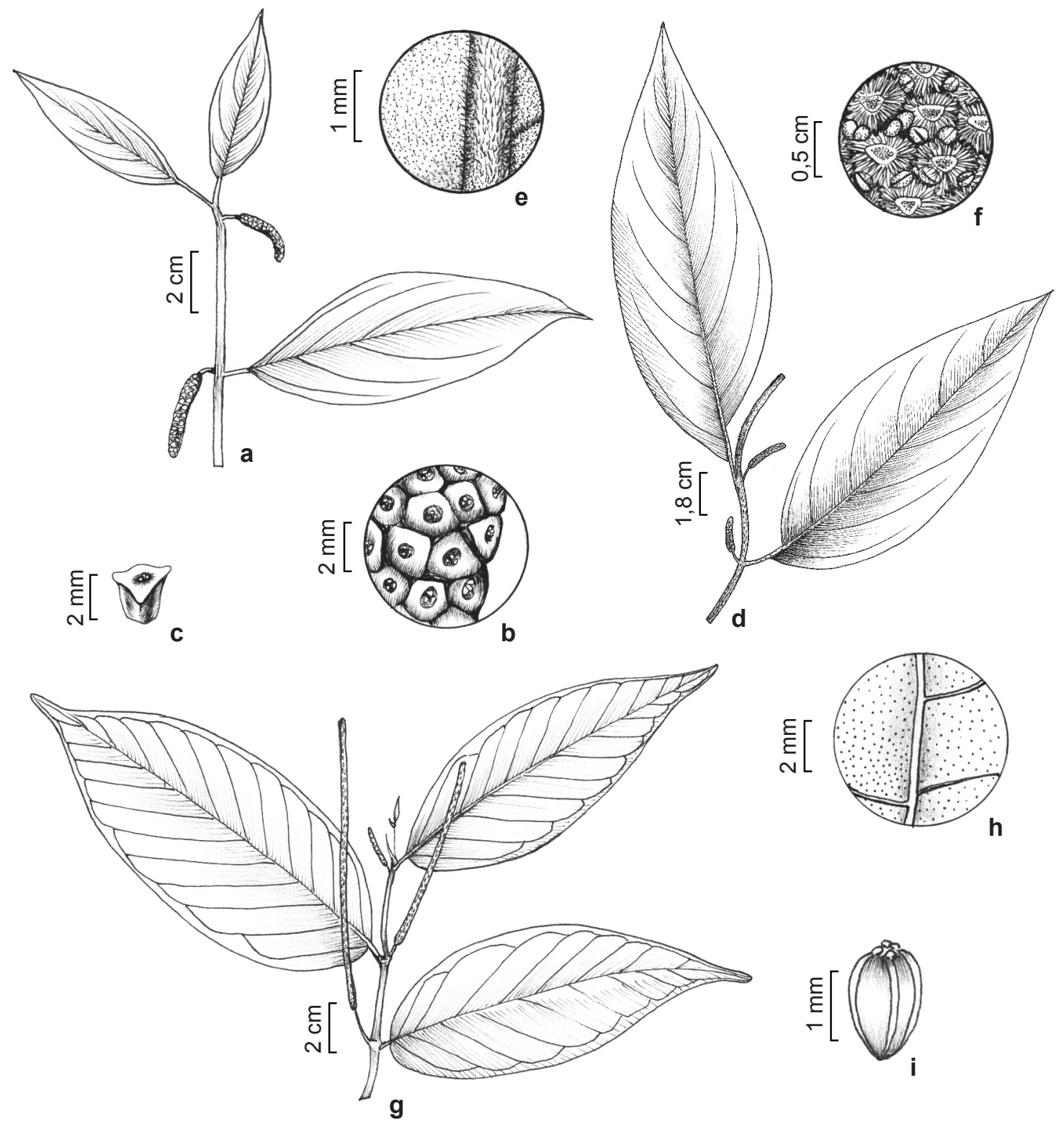

Figura 2 - a-c. Piper aleyreanum C. DC. - a. ramo fértil (A. Melo et al. 981); b. detalhe da espiga com frutos (A. Melo et al. 981); c. fruto individualizado (A. Melo et al. 981). d-f. Piper arboreum var. hirtellum Yunck. (A. Melo et al. 976) -d. ramo fértil; e. detalhe face abaxial da folha; f. detalhe da espiga em flor, evidenciando as brácteas florais. g-i. Piper bartlingianum (Miq.) C. DC. (A. Melo et al. 838) - g. ramo fértil; h. detalhe da face abaxial da folha; i. detalhe do fruto. Figure 2 - a-c. Piper aleyreanum C. DC. - a. fertile branch (A. Melo et al. 981); b. detail of spike with fruits (A. Melo et al. 981); c. fruit individualized (A. Melo et al. 981). d-f. Piper arboreum var. hirtellum Yunck. (A. Melo et al. 976) - d. fertile branch; e. detail of abaxial leaf surface; f. detail of spike with flowers, showing the flowers bracts. g-i. Piper bartlingianum (Miq.) C. DC. (A. Melo et al. $838)$ - g. fertile branch; h. detail of abaxial leaf surface; i. detail of fruit.

base assimétrica, $0,8-1,8 \mathrm{~cm}$ de diferença entre os lobos, arredondada, obtusa a cuneada, ápice agudo a acuminado, margem não ciliada; face adaxial glabra, face abaxial glabrescente a esparsamente hirsuta e com nervuras hirsutas, tricomas de um único tamanho; padrão de venação broquidódroma, nervuras secundárias 7-10 pares dispostas ao longo da nervura principal; pecíolo $0,5-1,5 \mathrm{~cm}$ compr., alado por toda sua extensão, glabrescente a densamente hirsuto. Espigas 5,3-12,6 $\times 0,1-0,2$ 
$\mathrm{cm}$, eretas, não apiculadas; pedúnculo 0,7-1,5 cm compr., minutamente ou densamente hirsuto; raque glabra. Flor estames-4; estigmas-3, sésseis; bráctea floral orbicular a triangular, fimbriada. Drupas $1-2 \times 0,3-0,5 \mathrm{~mm}$, tetragonais, não comprimidas lateralmente, ápice sem depressão, glandulares, glabras a pulverulentas.

Material selecionado: Grade do PPBio (L1), 24.XI.2006, fl., F.A. Carvalho 794 (INPA); Trilha de acesso à Grade do PPBio, 19.VIII.2012, fl. e fr., A. Melo et al. 976 (INPA, UFP); s.loc., 14.IX.2010, fl., S.O. Santos et al. 214 (INPA).

Distribuída no Panamá, Venezuela, Guiana, Suriname, Guiana Francesa e Brasil (Steyermark \& Callejas-Posada 2003). No país a espécie está presente na Mata Atlântica, Cerrado e Amazônia, nos estados do Amazonas e Acre (Guimarães et al. 2013), sendo aqui registrada em Roraima. Segundo Steyermark \& Callejas-Posada (2003), há duas variedades de Piper arboreum Aubl., que se diferenciam pela pilosidade nos ramos, folhas, pecíolos e pedúnculos, sendo $P$. arboreum var. arboreum completamente glabra, e $P$. arboreum var. hirtellum minuta e esparsamente puberulentas a hirsutas nas estruturas citadas. O táxon foi encontrado apenas em locais de Floresta de Terras Baixas, e diferencia-se dos demais principalmente pela grande diferença entre os lobos da base da folha $(0,8-1,8 \mathrm{~cm})$, além do pecíolo alado em toda a sua extensão.

2.3 Piper bartlingianum (Miq.) C. DC. in A. DC., Prodr. 16: 257. 1869.

Fig. 2g-i

Arbustos eretos 2-2,5 m alt., glândulas marrons presentes. Ramos glabros a pulverulentos. Folhas (10)13-20(22,5) × (3,5)5-9(10) cm, elípticas, oblongas, ovais a obovadas, base simétrica ou pouco assimétrica, arredondada ou raramente cuneada, ápice acuminado a agudo, margem não ciliada; glabras em ambas as faces, face abaxial glandular; padrão de venação broquidródroma, nervuras secundárias 6-10 pares dispostas ao longo da nervura principal; pecíolo 0,3-0,6 cm compr., canaliculado, pulverulento. Espigas 5-10,5 × 0,3-0,5 cm, eretas, não apiculadas; pedúnculo $0,8-1,5 \mathrm{~cm}$ compr., glabro a pulverulento; raque fimbriada. Flor estames-4; estigmas-4, sésseis; bráctea floral cuculada, margem não ciliada; pedicelo esparsamente fimbriado. Drupas $1-2 \times 1-1,5$ mm, elipsoides, sulcadas, não comprimidas lateralmente, ápice sem depressão, glandulares, glabras a pulverulentas.
Material selecionado: Grade do PPBio (L1), 24.XI.2006, fl., F.A. Carvalho 787 (INPA); Rio Barauana, Trilha do Pesquisador, 22.IX.2011, fr., A. Melo et al. 910A (INPA, RB, UFP); Trilha de acesso à Grade do PPBio, 15.IX.2011, fr., A. Melo et al. 838 (INPA, RB, UFP).

Distribuída na Colômbia, Venezuela, Guiana, Suriname, Guiana Francesa (Trelease \& Yuncker 1950; Steyermark \& Callejas-Posada 2003) e Brasil, onde está registrada nos estados de Roraima, Amapá, Amazonas, Pará, Acre, Rondônia, Mato Grosso e Ceará (Guimarães et al. 2013). A espécie foi encontrada em locais de Floresta de Terras Baixas, e diferencia-se pelas nervuras quando secas tornarem-se mais claras que o restante da lâmina, além das drupas sulcadas.

2.4 Piper consanguineum (Kunth) Steud., Nomencl. bot. ed. 2, 2: 340. 1841. Fig. 3a-b

Arbustos eretos 0,3-0,5(1,5) m alt. Ramos avermelhados quando frescos, estrigosos. Folhas 5-9(13) × 1-3(4) cm, oblongas a elípticas, ou raro ovadas, base assimétrica, diferença até $0,6 \mathrm{~cm}$ entre os lobos, arredondada a cordada, ápice agudo, margem não ciliada; face adaxial glabra, face abaxial glabra e nervuras estrigosas, com tricomas de um único tamanho, glandular; padrão de venação broquidródromo, nervuras secundárias 6-8 pares dispostas ao longo da nervura principal; pecíolo $0,1-0,7 \mathrm{~cm}$ compr., sulcado na base, estrigoso. Espigas $1-3 \times 0,3-0,4$ $\mathrm{cm}$, eretas, apiculadas; pedúnculo $3-5 \mathrm{~mm}$ compr., piloso ou estrigoso; raque glabra. Flor estames-2; estigmas-3, estilete desenvolvido de até $0,5 \mathrm{~mm}$ compr.; bráctea floral cuculada, levemente ciliada na parte central ou totalmente não ciliada. Drupas 1-1,5×0,5-1 mm, globoides, comprimidas lateralmente, ápice com depressão, glandulares, glabras.

Material selecionado: Grade do PPBio(L1), 27.V.2006, fl., F.R.C. Costa 1121 (INPA); 24.XI.2006, fr., F.A. Carvalho 798 (INPA); Trilha de acesso à Grade do PPBio, 12.X.2011, fl. e fr., A. Melo et al. 928 (INPA, RB, UFP).

Distribuída pela Venezuela, Guiana, Guiana Francesa, Suriname e Amazônia Brasileira (Steyermark \& Callejas-Posada 2003), onde ocorre nos estados do Amazonas, Acre, Pará e Amapá (Guimarães et al. 2013), sendo aqui registrada em Roraima. Habita locais de Floresta de Terras Baixas e pode ser diferenciada das demais espécies por geralmente possuir menor porte, nervuras da face abaxial estrigosas e avermelhadas quando frescas. 


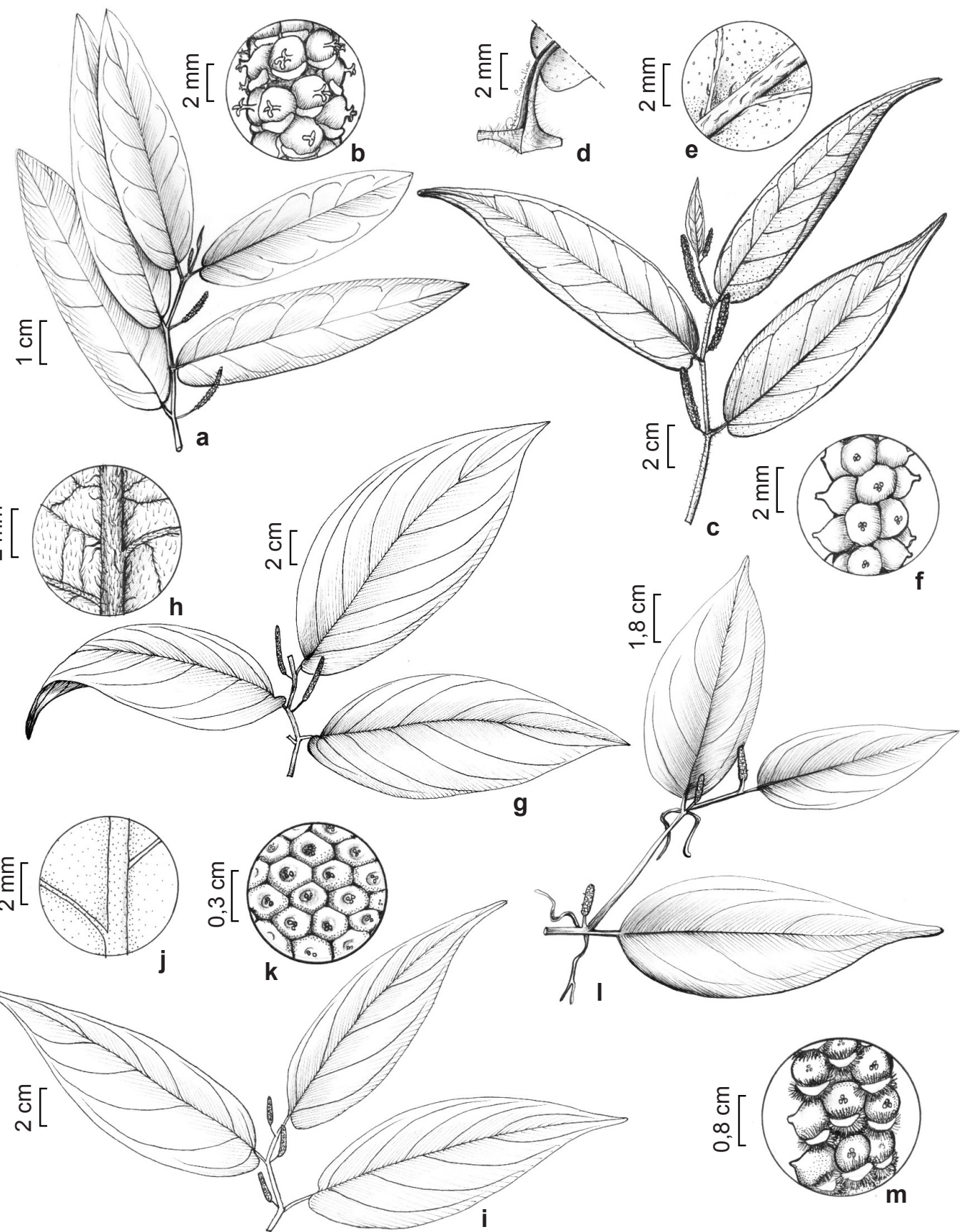

Figura 3 - a-b. Piper consanguineum (Kunth) Steud. (A. Melo et al. 928) - a. ramo fértil; b. detalhe da espiga. c-f. P. cyrtopodon (Miq.) C. DC. (A. Melo et al. 842) - c. ramo fértil; d. detalhe da face abaxial da folha; e. detalhe do pecíolo; f. detalhe da espiga com frutos. g-h. P. demeraranum (Miq.) C. DC. (A. Melo et al. 907) - g. ramo fértil; h. detalhe da face abaxial da folha. i-k. Piper glabrescens (Miq.) C. DC. - i. ramo fértil (A. Melo et al. 841); j. detalhe da face abaxial da folha (A. Melo et al. 841); k. detalhe da espiga com frutos (A. Melo et al. 982). 1-m. Piper goeldii C. DC. (A. Melo \& W.S. Batista 1041) - 1. ramo fértil; m. detalhe da espiga com frutos.

Figure 3 - a-b. Piper consanguineum (Kunth) Steud. (A. Melo et al. 928) - a. fertile branch; b. detail of spike. c-f. Piper cyrtopodon (Miq.) C. DC. (A. Melo et al. 842) - c. fertile branch; d. detail of abaxial leaf surface; e. detail of petiole; f. detail of spike with fruits. g-h. Piper demeraranum (Miq.) C. DC. (A. Melo et al. 907) - g. fertile branch; h. detail of abaxial leaf surface. i-k. Piper glabrescens (Miq.) C. DC. - i. fertile branch (A. Melo et al. 841); j. detail of abaxial leaf surface (A. Melo et al. 841); k. detail of spike with fruits ( $A$. Melo et al. 982). 1-m. Piper goeldii C. DC. (A. Melo \& W.S. Batista 1041) - 1. fertile branch; m. detail of spike with fruits. 
2.5 Piper cyrtopodon (Miq.) C. DC. in A. DC., Prodr. 16: 337.1869.

Fig. 3c-f

Arbustos eretos até $2 \mathrm{~m}$ alt. Ramos jovens pilosos, tricomas 1-2 mm compr. Folhas 10-18,5 $\times 3-5,5 \mathrm{~cm}$, oblongas a elípticas, base assimétrica, diferença $0,1-0,2 \mathrm{~cm}$ entre os lobos, cordada, ápice agudo a acuminado, margem não ciliada; face adaxial glabra; face abaxial glabra e nervuras esparsamente pilosas, tricomas até $1 \mathrm{~mm}$ compr. e de um único tamanho, glândulas marrons presentes; padrão de venação broquidódromo, nervuras secundárias 6-10 pares dispostas ao longo da nervura principal; pecíolo $0,5-1 \mathrm{~cm}$ compr., sulcado na base ou alado por toda sua extensão, piloso. Espigas 2,5-4 × 0,5-0,6 cm, eretas, não apiculadas; pedúnculo 0,5-1 $\mathrm{cm}$ compr., piloso; raque glabra. Flor estames-2; estigmas- 3 , estilete de aproximadamente $0,5 \mathrm{~mm}$ compr.; bráctea floral cuculada, fimbriada. Drupas $1-2,5 \times 1-3 \mathrm{~mm}$, globoides, não comprimidas lateralmente, apiculadas, ápice sem depressão, glandulares, glabras.

Material examinado: Grade do PPBio, 21.X.2011, fr., $A$. Melo et al. 929 (INPA, UFP); Trilha de acesso à Grade do PPBio, 15.IX.2011, fr., A. Melo et al. 842 (INPA, UFP).

Material adicional examinado: BRASIL. AMAZONAS: Manaus, Reserva Florestal Adolfo Ducke, 7.VIII.1995, fl. e fr., M. Nee 46205 (INPA, MG).

Presente na Guiana e Amazônia Brasileira (Trelease \& Yuncker 1950), onde ocorre nos estados do Amapá, Amazonas, Pará e Mato Grosso (Guimarães et al. 2013), sendo aqui registrada em Roraima. Encontrada em locais de Floresta de Terras Baixas e diferencia-se dos demais táxons da área por possuir tricomas longos nos ramos (1-2 mm compr.), folhas de base cordada e frutos apiculados.

2.6 Piper demeraranum (Miq.) C. DC. in A. DC., Prodr. 16: 298. 1869.

Fig. 3g-h

Arbustos eretos até $2 \mathrm{~m}$ alt. Ramos pilosos. Folhas (14)16-23 × (4,5)5-9,5 cm, oblongas, elípticas a obovadas, base assimétrica, diferença $0,5-0,6 \mathrm{~cm}$ entre os lobos, lobadas ou auriculadas, lobo inferior sobrepondo-se ao pecíolo, ápice agudo, margem esparsamente ciliada; face adaxial glabra ou pilosa apenas nas ner.vuras; face abaxial pilosa, nervuras pilosas, tricomas de diferentes comprimentos, glandulares; padrão de venação eucamptódromo, nervuras secundárias 10-12 pares dispostas ao longo da nervura principal; pecíolo 0,3$1,2 \mathrm{~cm}$ compr., sulcado na base; densamente pilosos. Espigas 2-3,2 cm compr., eretas, não apiculadas; pedúnculo $0,5-1 \mathrm{~cm}$ compr., piloso; raque fimbriada. Flor estames-4; estigmas-3, sésseis; bráctea floral triangular, margem levemente ciliada. Drupas 2-3 $\times 1-2 \mathrm{~mm}$, tetragonais, comprimidas lateralmente, ápice sem depressão, puberulentas.

Material examinado: Rio Barauana, Trilha do Pesquisador, 21.IX.2011, fl., A. Melo et al. 907 (INPA, UFP); Trilha de acesso à Grade do PPBio, 10.XI.2011, fl., A. Melo \& E. Pessoa 924 (INPA, RB, UFP).

Material adicional: BRASIL. AMAZONAS: Manaus, Reserva Florestal Adolpho Ducke, 7.VIII.1995, fl., M. Nee et al. 46201 (INPA). RORAIMA: Amajari, Auaris, 7.IX.1969, fr., G.T. Prance et al. 9682 (INPA, R, RB).

Distribuída em Trindade, Venezuela, Guiana, Suriname, Guiana Francesa e Amazônia Brasileira, nos estados do Acre, Rondônia, Mato Grosso, Amazonas, Roraima e Pará (Trelease \& Yuncker 1950; Guimarães et al. 2013). Na área foi encontrada em Floresta de Terras Baixas, sendo distinta dos demais táxons por suas folhas com um dos lobos que forma uma aurícula e que se sobrepõe ao pecíolo.

2.7 Piper glabrescens (Miq.) C. DC. in A. DC., Prodr. 16: 271. $1869 . \quad$ Fig. 3i-k

Arbustos eretos até $2 \mathrm{~m}$ alt. Ramos glabros à puberulentos, glandulares. Folhas 13-21 × 5,5-9 $\mathrm{cm}$, elípticas, oblongas a ovadas, base simétrica ou pouco assimétrica, diferença até $0,2 \mathrm{~cm}$ entre os lobos, lobo inferior arredondado a levemente lobado, lobo superior arredondado a obtuso, ápice atenuado a acuminado, margem não ciliada; face adaxial glabra a glabrescente; face adaxial glabra a glabrescente e glandular; padrão de venação eucamptódromo, nervuras secundárias 5-7 pares distribuídas ao longo da nervura principal; pecíolo 0,8-1,5 cm compr., sulcado na base ou alado por toda sua extensão, glabro a puberulento. Espigas 1,5-3 × 0,4-0,6 cm, eretas, apiculadas; pedúnculo 0,4-1 cm compr., glabro a pulverulento; raque glabra. Flor estames-4; estigmas-3, sésseis; bráctea floral cuculada, esparso e minutamente fimbriada ou fimbriada nos vértices, glandular. Drupas $1-2 \times 1-2$ $\mathrm{mm}$, tetragonais, comprimidas lateralmente, ápice com depressão, glandulares, glabras.

Material examinado: Grade do PPBio (L2), 25.XI.2006, fl., F.A. Carvalho 834 (INPA); Rio Barauana, Trilha do Pesquisador, 22.IX.2011, fr., A. Melo et al. $910 B$ (INPA, UFP); Trilha de acesso à Grade do PPBio, 15.IX.2011, fl. e fr., A. Melo et al. 841 (INPA, RB, UFP).

Distribuída em Trindade, Venezuela, Guiana e Suriname (Trelease \& Yuncker 1950; CallejasPosada et al. 2007), sendo aqui registrada para o Brasil. Segundo Trelease \& Yuncker (1950) há três variedades para a espécie que se diferenciam pela pilosidade ao longo das nervuras da face abaxial da folha e da margem da bráctea floral. Apesar das 
amostras analisadas da área apresentarem folhas glabras, as brácteas apresentaram variação na sua margem, e então não enquadramos em nenhuma das variedades. Na área de estudo o táxon foi encontrado em locais de Floresta de Terras Baixas, e diferencia-se das demais espécies pelas folhas com base simétrica a levemente assimétrica, arredondada, obtusa a levemente lobado, com até 7 pares de nervuras secundárias, espigas curtas, espessas $(1,5-3 \times 0,4-1 \mathrm{~cm})$ e apiculadas.

2.8 Piper goeldii C. DC., Notizbl. Königl. Bot. Gart. Berlin 6(62): 434. $1917 . \quad$ Fig. 31-m

Hemiepífitas 1,5-5 m alt., glândulas marrons presentes. Ramos pilosos, glandulares. Folhas 8,5-18 $\times 3,4-7 \mathrm{~cm}$, oblongas, a elípticas, base simétrica ou pouco assimétrica, diferença $0,1-0,3 \mathrm{~cm}$ entre os lobos, cuneada a arredondada, ápice agudo a atenuado, margem não ciliada; face adaxial glabra; face abaxial glabra a glabrescente e estrigosas nas nervuras, tricomas de um único tamanho,glandular; padrão de venação eucamptódromo ou broquidódromo, nervuras secundárias 3-6 pares dispostas até próximo à porção mediana da folha ou ao longo da nervura principal; pecíolo 0,2-1,8 cm compr., alado, piloso. Espigas 0,5-2,7 ×0,2-0,3 cm, eretas, não apiculadas; pedúnculo $0,2-0,5 \mathrm{~cm}$ compr., pulverulento a piloso; raque glabra. Flores estames-4; estigmas-3 com estilete desenvolvido; bráctea floral triangular, fimbriada. Drupas 1,5-2 × 1,5-2 mm, globoides, comprimidas lateralmente, ápice sem depressão, glandulares, puberulentas.

Material selecionado: Grade do PPBio (L1 800-1.200), 26.VIII.2012, fl. e fr., A. Melo \& W.S. Batista 1041 (INPA, UFP); Grade do PPBio (L3), 20.I.2012, fl., P.A. Pereira et al. 142 (INPA).

Considerada endêmica do Brasil e registrada até o momento apenas no estado do Amazonas (Guimarães et al. 2013), sendo aqui registrada em Roraima. No Viruá foi encontrada apenas em áreas de Campinaranas Florestadas, e distingue-se das demais espécies principalmente pelo seu hábito, mas também pela presença de poucas nervuras secundárias (3-6 pares) e espigas curtas $(0,5-2,7 \mathrm{~cm}$ compr.).

\subsection{Piper hispidum Sw., Prodr.: 15. 1788.}

Fig. 4a-c

Arbustos eretos até $2 \mathrm{~m}$ alt., glândulas marrons presentes. Ramos esparsamente estrigosos. Folhas 8,5-19,3 × 3,3-11,6 cm, ovadas a elípticas, base assimétrica, diferença até $0,5 \mathrm{~cm}$ entre os lobos, lobo inferior arredondado a truncado, lobo superior cuneado, ápice agudo a acuminado, margem não ciliada a esparsamente ciliada; face adaxial híspida na face adaxial e mais concentrados nas nervuras, áspera ao toque, face abaxial glabra ou esparsamente pilosa, nervuras pilosas, glandular; padrão de venação eucamptódromo, nervuras secundárias 4-5 pares dispostas até próximo a porção mediana da nervura principal; pecíolo 0,4-1,4 cm compr., cilíndrico ou sulcado na base, pilosos. Espigas 5-10 × 0,2-0,25 cm, eretas, apiculadas; pedúnculo 4-1,2 mm compr., piloso; raque fimbriada. Flor estames-4; estigmas-3, sésseis; bráctea floral triangular a levemente orbicular, densamente fimbriada. Drupas 0,7-1,2 × 0,3-0,8 mm, ovoides a tetragonais, comprimidas lateralmente, ápice com depressão, glandulares, pilosas.

Material examinado: Estrada de acesso à Sede do PARNA, 25.X.2011, fl. e fr., A. Melo et al. 942 (INPA, UFP); 19.VIII.2012, fl. e fr., A. Melo \& W.S. Batista 993 (INPA, UFP).

Presente desde a América Central, Ilhas Caribenhas a América do Sul (Trelease \& Yuncker 1950). No Brasil ocorre no Cerrado, Mata Atlântica e Amazônia, nos estados de Roraima, Amapá, Amazonas, Pará, Acre e Mato Grosso (Guimarães et al. 2013). Steyermark \& Callejas-Posada (2003) consideraram Piper hispidum como sendo bastante variável quanto à forma da folha e pilosidade, não considerando táxons infraespecíficos. No PARNA Viruá o táxon foi encontrado em bordas de Floresta de Terras Baixas e é de fácil identificação por possuir a face adaxial áspera ao toque e poucas nervuras secundárias (4-5 pares) que se dispõem até próximo à porção mediana da folha.

2.10 Piper hostmannianum (Miq.) C. DC. in A. DC., Prodr. 16: 287. $1869 . \quad$ Fig. 4d-f Arbustos eretos até $2 \mathrm{~m}$ alt. Ramos pulverulentos a pilosos. Folhas $11-22,5 \times 5-12,9$ $\mathrm{cm}$, elípticas, ovadas a lanceoladas, base assimétrica, diferença de 0,3-0,5 cm entre os lobos, lobo inferior arredondado ou levemente lobado, lobo superior cuneado ou raramente arredondado, ápice agudo a atenuado, margem não ciliada; face adaxial glabra; face abaxial glabrescente a pilosa, nervuras pilosas, tricomas de um único tamanho, glandular; padrão de venação broquidódromo ou eucamptódromo, 3-6 pares de nervuras secundárias ascendentes dispostas até a porção mediana ou desenvolvidas ao longo da nervura principal, 10-15 pares de nervuras de menor calibre seguindo em direção à margem da folha; pecíolo 0,5-1,5 cm compr., sulcado na base, 


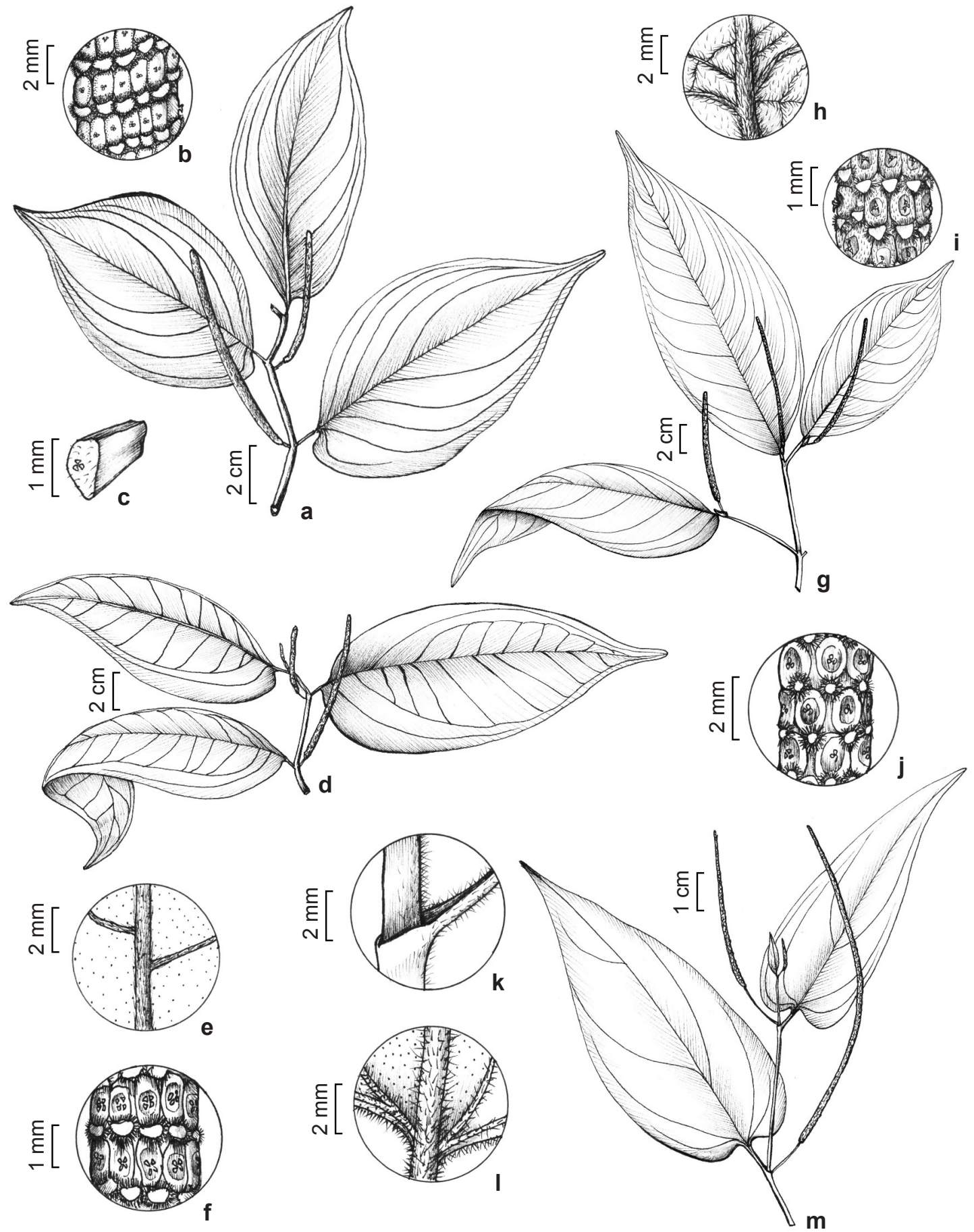

Figura 4 - a-c. Piper hispidum Sw. (A. Melo et al. 942) - a. ramo fértil; b. detalhe da espiga com frutos; c. fruto individualizado. d-f. Piper hostmannianum (Miq.) C. DC. (A. Melo et al. 845) - d. ramo fértil; e. detalhe da face abaxial; f. detalhe da espiga em fruto. g-i. Piper plurinervosum Yunck. (A. Melo et al. 843) - g. ramo fértil; h. detalhe da face abaxial da folha; i. detalhe da espiga em fruto. j-m. Piper schwackei C. DC. (A. Melo et al. 935) - j. espiga em fruto; $k$. detalhe do pecíolo; 1 . detalhe da face abaxial; $\mathrm{m}$. ramo fértil.

Figure 4 -a-c. Piper hispidum Sw. (A. Melo et al. 942) - a. fertile branch; b. detail of spike with fruits; c. druit individualized. d-f. Piper hostmannianum (Miq.) C. DC. (A. Melo et al. 845) - d. fertile branch; e. detail of abaxial leaf surface; f. detail of spike with fruits. g-i. Piper plurinervosum Yunck. (A. Melo et al. 843) - g. fertile branch; h. detail of abaxial leaf surface; i. detail of spike with fruit. j-m. Piper schwackei C. DC. (A. Melo et al. 935) - j. detail of spike with fruits; k. detail of petiole; l. detail of abaxial leaf surface; $\mathrm{m}$. fertile branch. 
esparsamente piloso a densamente piloso. Espigas 5,8-10,7 × 0,2-0,3 cm, eretas, não apiculadas; pedúnculo 0,5-1 cm compr., puberulento a piloso; raque glabra. Flor estames-4; estigmas-3, sésseis; bráctea floral triangular, orbicular a elíptica, fimbriada. Drupas 0,5-1 ×0,3-0,5 mm, tetragonais, comprimidas lateralmente, ápice com depressão, puberulentas a pilosas.

Material examinado: Estrada de acesso à Sede do PARNA, 26.VII.2011, fl., P.A. Pereira et al. 64 (INPA); Rio Barauana, 2.XII.2006, fr., F.A. Carvalho \& R. Nascimento 1074 (INPA); Trilha de acesso à Grade do PPBio, 15.IX.2011, fl. e fr., A. Melo et al. 845 (INPA, RB, UFP).

Distribuída pela Venezuela, Guiana, Guiana Francesa, Suriname e Amazônia Brasileira, nos estados do Amapá, Amazonas, Pará e Acre (Trelease \& Yuncker 1950; Steyermark \& Callejas-Posada 2003; Guimarães et al. 2013), sendo aqui registrada em Roraima. Uma das espécies mais comuns da área, pode ser diferenciada das demais por possuir 3-6 pares de nervuras secundárias ascendentes e que estão distribuídas até a porção mediana da folha, espigas de 5,8-10,7 cm compr. e eretas. Foi encontrada em locaisde Floresta de Terras Baixas e também em Campinarana Florestada.

2.11 Piper plurinervosum Yunck., Bol. Inst. Bot. 3: 62.1966.

Fig. 4g-i

Arbustos eretos até $2 \mathrm{~m}$ alt. Ramos vilosos. Folhas 15-26,5 × 6-11,5 cm, elípticas a oblongas, base simétrica ou levemente assimétrica, diferença até $0,4 \mathrm{~cm}$ entre os lobos, arredondada a cuneada, ápice agudo, margem não ciliada; face adaxial glabra; face abaxial vilosa, densamente pilosa nas nervuras, tricomas de um único tamanho, glandular; padrão de venação eucamptódromo, nervuras secundárias 9-11 pares dispostas ao longo da nervura principal; pecíolo 0,7-1,3 cm compr., sulcado na base ou alado por toda a extensão, viloso. Espigas $4-10,5 \times 0,15-0,25 \mathrm{~cm}$, rosadas quando frescas, eretas, apiculadas; pedúnculo 0,6-1,3 cm compr., piloso; raque fimbriada. Flor estames-3; estigmas-3, sésseis; bráctea floral cuculada, fimbriada, com fimbrias de maior tamanho na parte inferior da bráctea. Drupas 0,8-1,2 $\times$ 0,5-1 mm, tetragonais, comprimidas lateralmente, ápice com depressão, glandulares, densamente pilosas.

Material examinado: Grade do PPBio, 8.VII.2011, fr., $K$. Cangani 152 (INPA, UFP); Trilha de acesso à Grade do PPBio, 15.IX.2011, fr., A. Melo et al. 843 (INPA, UFP). Material adicional: BRASIL. AMAZONAS: Manaus, Cachoeira do Tarumã, 27.V.1955, fl., J. Chagas s.n. (INPA 1075-Isótipo).
Considerada endêmica do Brasil e com ocorrência na Amazônia, nos estados do Amazonas e Rondônia e Mata Atlântica da Bahia (Guimarães et al. 2013), tendo aqui o seu primeiro registro em Roraima. Ocorre em locais de Floresta de Terras Baixas e diferencia-se das demais espécies pelas folhas grandes (15-26,5 cm compr.), presença de 9-11 pares de nervuras secundárias, face abaxial vilosa e espigas rosadas quando frescas.

2.12 Piper schwackei C. DC., Notizbl. Königl. Bot. Gart. Berlin 6: 443. $1917 . \quad$ Fig. 4j-m

Arbustos escandentes até $2 \mathrm{~m}$ alt. Ramos glabros a glabrescentes. Folhas (6)8-11(13) $\times$ $(2,5) 3,5-4,5(5) \mathrm{cm}$, lanceoladas, base simétrica ou levemente assimétrica, lobada, raramente arredondada ou truncada, ápice atenuado, margem não ciliada; face adaxial glabra; face abaxial glabra, nervuras pilosas, tricomas de um único tamanho, glandular; padrão de venação eucamptódromo, 1-2 pares de nervuras secundárias surgindo da base, e mais um par surgindo até a porção mediana da nervura principal; pecíolo 1-3 cm compr., alado até a metade ou por toda sua extensão, piloso até a base da folha. Espigas (4)6-10 × 0,1-0,15 cm, eretas, não apiculadas; pedúnculo $0,8-2 \mathrm{~cm}$ compr., glabro ou glabrescente; raque glabra. Flor estames-4; estigmas-3, sésseis; bráctea floral orbicular a triangular, fimbriada. Drupas 0,5-1 ×0,3-0,5 mm, tetragonais, comprimidas lateralmente, ápice sem depressão, glandulares, glabras.

Material examinado: Margem do Rio Barauana, 19.X.2011, fl. e fr., A. Melo et al. 935 (INPA, RB, UFP). Material adicional: BRASIL. AMAZONAS: Rio Uatumã, 20.II.1978, fl. e fr., P. Lisbôa et al. 1119 (INPA).

Considerada endêmica do Brasil, está presente apenas na Amazônia dos estados do Amazonas, Pará, Acre e Maranhão (Yuncker 1972; Guimarães et al. 2013), sendo aqui registrada em Roraima. A espécie foi encontrada em locais de Floresta de Várzea e é de fácil reconhecimento por ser um arbusto escandente, possuir folhas lanceoladas, de base simétrica ou levemente assimétrica, lobada, raramente truncada ou arredondada, e ápice atenuado.

\section{Agradecimentos}

Os autores agradecem as instituições que financiaram esta pesquisa de alguma forma, incluindo o CNPq, CAPES e FACEPE (AMD 126-2011); ao Instituto Nacional de Pesquisas da Amazônia (INPA); à Regina Carvalho, as ilustrações; aos curadores dos herbários 
consultados; à Dra. R. Forzza e Dra. M. R. Barbosa, os comentários importantes sobre o manuscrito e aos gestores do Parque Nacional do Viruá: MSc. Antônio Lisboa e Biól. Beatriz Lisboa, assim como toda a equipe do PARNA.

\section{Referências}

Bardelli, K.C.; Kirizawa, M. \& Sousa, A.V.G. 2008. O gênero Piper L. (Piperaceae) da Mata Atlântica da Microbacia do Sítio Cabuçu-Proguaru, Guarulhos, SP, Brasil. Hoehnea 35: 553-561.

Brasil 1998. Decreto s/nº de 29 de abril de 1998. Cria o Parque Nacional do Viruá, no estado de Roraima, e dá outras providências. Brasília, 29 de abril de 1998. Disponível em <http://www.planalto.gov. br/ccivil_03/DNN/Anterior\%20a\%202000/1998/ Dnn29-04-98-1.htm>. Acesso em 2 Dez 2012.

Callejas-Posada, R. 1995. Piperaceae. In: Stannard, B.L. (ed.). Flora do Pico das Almas. Royal Botanical Gardens, Kew. Pp. 530-534.

Callejas-Posada, R. 2008. Piperaceae. In: Daly, D.C. \& Silveira, M. (eds.). Flora do Acre, Brasil. EDUFAC, Rio Branco. Pp. 296-305.

Callejas-Posada, R.; Görts-van Rijn, A.R.A.; Steyermark, J.A. 2007. Piperaceae. In: Funk, V.; Hollowell, T.; Berry, P.; Kelloff, C. \& Alexander, S.N. (eds.). Checklist of the plants of the Guiana Shield (Venezuela: Amazonas, Bolivar, Delta Amacuro; Guyana, Surinam, French Guiana). Contributions from the United States National Herbarium 55: 458-466.

Carvalho-Okano, R.M. \& Alves, S.A.M. 1998. Piperaceae C. Agardh da Estação Experimental Mata do Paraíso, Viçosa, MG. Acta Botanica Brasilica 12 (supl.): 497-513.

Carvalho-Silva, M. \& Cavalcanti, T.B. 2002. Flora do Distrito Federal, Brasil: Piperaceae. In: Cavalcanti, T.B. \& Ramos, A.E. (orgs.). Flora do Distrito Federal, Brasil. Vol. 2. Embrapa Recursos Genéticos e Biotecnologia, Brasília. Pp. 93-124.

Carvalho-Silva, M. \& Guimarães, E.F. 2009. Piperaceae do Parque Nacional da Serra da Canastra, Minas Gerais, Brasil. Boletim de Botânica da Universidade de São Paulo 27: 235-245.

Costa, M.A.S. \& Callejas-Posada, R. 1999. Piperaceae. In: Ribeiro, J.E.L.S; Hopkins, M.J.G.; Vicentini, A.; Sothers, C.A.; Costa, M.A.S.; Brito, J.M.; Souza, M.A.D.; Martins, L.H.P.; Lohmann, L.G.; Assunção, P.A.C.L.; Pereira, E.C.; Silva, C.F.; Mesquita, M.R. \& Procópio, L.C. (eds.). Flora da Reserva Ducke: Guia de identificação das plantas vasculares de uma floresta de terra-firme na Amazônia Central. Instituto Nacional de Pesquisas da Amazônia, Manaus. Pp. 181-187.

Di Stasi, L.C.; Hiruma-Lima, C.A.; Mariot, A.; Portilho, W.G. \& Reis, M.S. 2002. Piperales medicinais.
In: Di Stasi, L.C. \& Hiruma-Lima, C.A. Plantas medicinais na Amazônia e na Mata Atlântica. Editora UNESP, São Paulo. Pp. 120-138.

Görts-van Rijn, A.R.A. 2002. Piperaceae. In: Mori, S.A.; Cremers, G.; Gracie, C.A.; Granville, J.J.; Heald, S.C.; Hoff, M. \& Mitchell, J.D. (eds.). Guide to the vascular plants of central French Guiana. The New York Botanical Garden Press, New York. Pp. 574-584.

Guimarães, E. F. 1999. Piperaceae. In: Melo, M.M.R.F.; Barros, F.; Cjiea, S.A.C.; Kirizawa, M.; JungMendaçolli, S.L. \& Wanderley, M.G.L. (eds.). Flora fanerogâmica da Ilha do Cardoso. Vol. 6. Instituto de Botânica de São Paulo, São Paulo. Pp. 15-43.

Guimarães, E.F. \& Carvalho-Silva, M. 2012. Piperaceae. In: Wanderley, M.G.L.; Shepherd, G.J.; Melhem, T.S.; Giulietti, A.M. \& Martins, S.E. (orgs.). Flora fanerogâmica do estado de São Paulo. Vol. 7. FAPESP, São Paulo. Pp. 263-320.

Guimarães, E.F.; Carvalho-Silva, M. \& Cavalcanti, T.B. 2007. Flora dos estados de Goiás e Tocantins: Piperaceae. Universidade Federal de Goiás, Goiânia. 68p.

Guimarães, E.F.; Carvalho-Silva, M.; Monteiro, D. \& Medeiros, E. 2013. Piperaceae. In: Lista de espécies da flora do Brasil. Jardim Botânico do Rio de Janeiro. Disponível em <http://floradobrasil.jbrj. gov.br/jabot/floradobrasil/FB12609>. Acesso em 25 Out 2013.

Guimarães, E.F. \& Giordano, L.S.C. 2004. Piperaceae do Nordeste brasileiro I: estado do Ceará. Rodriguésia 55: 21-46.

Guimarães, E.F.; Ichaso, C.L.F. \& Costa, C.G. 1984. Flora ilustrada catarinense. Piperácea. 4. Peperomia. Herbário Barbosa Rodrigues, Itajaí. 136p.

Guimarães, E.F. \& Monteiro, D. 2006. Piperaceae da Reserva Biológica de Poço das Antas, Silva Jardim, Rio de Janeiro, Brasil. Rodriguésia 57: 567-587.

Guimarães, E.F. \& Valente, M.C. 2001. PiperaceaePiper. In: Reitz, R. (ed.). Flora ilustrada catarinense. Herbário Barbosa Rodrigues, Itajaí. 104p.

Harris, J. \& Harris, M.W. 2001. Plant identification terminology: an illustrated glossary. $2^{\circ}$ ed. Spring Lake Publishing, Utah. 206p.

Hickey, L.J. 1974. Clasificación de la arquitectura de las hojas de dicotiledóneas. Boletín de La Sociedad Argentina de Botánica 16: 1-26.

IBGE. 2012. Manual técnico da vegetação brasileira. IBGE, Rio de Janeiro. 275p.

Ichaso, C.L.F.; Costa, C.G. \& Guimarães, E.F. 1977. Piperaceae do município do Rio de Janeiro. Arquivos do Jardim Botânico do Rio de Janeiro 20: 145-187.

Medeiros, E.S.S. \& Guimarães, E.F. 2007. Piperaceae do Parque Estadual de Ibitipoca, Minas Gerais, Brasil. Boletim de Botânica 25: 227-252. 
Melo, A.; Araújo, A.A.M. \& Alves, M. 2013. Flora da Usina São José: Aristolochiaceae e Piperaceae. Rodriguésia 64: 543-553.

Monteiro, D. \& Guimarães, E.F. 2008. Flora do Parque Nacional do Itatiaia, Brasil: Peperomia (Piperaceae). Rodriguésia 59: 161-195.

Monteiro, D. \& Guimarães, E.F. 2009. Flora do Parque Nacional do Itatiaia, Brasil: Manekia e Piper (Piperaceae). Rodriguésia 60: 999-1024.

Mori, S.A.; Mattos-Silva, L.A.; Lisboa, G. \& Coradin, L. 1989. Manual de manejo do herbário fanerogâmico. $2^{\mathrm{a}}$ ed. CEPLAC, Ilhéus. 104p.

Quijano-Abril, M.A.; Callejas-Posada, R. \& MirandaEsquivel, D.R. 2006. Areas of endemism and distribution patterns for Neotropical Piper species (Piperaceae). Journal of Biogeography 33: 1266-1278.

Samain, M.S.; Mathieu, G.; Wanke, S.; Neinhuis, C. \& Goetghebeur, P. 2008. Verhuellia revisitedunravelling its intricate taxonomic history and a new subfamilial classification of Piperaceae. Taxon 57: 583-587.

Schaefer, C.E.G.R.; Mendonça, B.A.F. \& Filho, E.I.F. 2009. Geoambientes e paisagens do Parque Nacional do Viruá-RR. Esboço de integração da geomorfologia, climatologia, solos, hidrologia e ecologia. Zoneamento Preliminar. ICMBio, Boa Vista. 59p.

Steyermark, J.A. \& Callejas-Posada, R. 2003. Piperaceae. In: Steyermark, J.A.; Berry, P.E.; Yatskievych, K. \& Holst, B. (eds.). Flora of the Venezuela Guayana.
Vol. 7. Missouri Botanical Garden Press, St. Louis. Pp. 681-738.

Suwanphakdee, C. \& Chantaranothai, P. 2009. The monotypic genus Zippelia Blume (Piperaceae): a new record for Thailand. Thai Forest Bulletin (Botany) 37: 147-150.

Tebbs, M.C. 1993. Piperaceae. In: Kubitzi, K.; Rohwer, J.G. \& Bittrich, V. (eds.). Flowering plants: Dicotyledons. Magnoliid, Hamamelid and Caryophyllid families. Vol. 2. Springer-Verlag, Berlin. Pp. 516-520.

Thiers, B. [continuously updated]. Index Herbariorum: A global directory of public herbaria and associated staff. New York Botanical Garden's Virtual Herbarium. Disponível em < http://sweetgum.nybg. org/ih/>. Acesso em 21 Jun 2013.

Trelease, W. \& Yuncker, T.G. 1950. The Piperaceae of Northern South America. 2 vols. University of Illinois Press, Urbana. 838p.

Wanke, S.; Samain, M.S.; Vanderschaeve, L.; Mathieu, G.; Goetghebeur, P. \& Neinhuis, C. 2006. Phylogeny of the genus Peperomia (Piperaceae) inferred from the $\operatorname{trnK} /$ matK region (cpDNA). Plant Biology 8: 93-102.

Yuncker, T.G. 1972. The Piperaceae of Brazil. Piper, Group I, II, III, IV. Hoehnea 2: 19-366.

Yuncker, T.G. 1973. The Piperaceae of Brazil II. Piper, Group V: Ottonia, Pothomorphe, Sarcorhachis. Hoehnea 3: 29-284.

Yuncker, T.G. 1974. The Piperaceae of Brazil III. Peperomia: Taxa of uncertain status. Hoehnea 4: 71-413.

\section{Lista de exsicatas}

Cabral, F.R. 244 (2.3). Cangani, K.G. 147 (2.3), 152 (2.11). Carvalho, F.A. 836, 845, 787, 841 (2.3), 849, 798 (2.4), 801 (2.5), 834 (2.7), 796, 803, 837 (2.8), 791, 805, 1072, 1074 (2.10). Chagas, J. s.n. INPA 1991 (2.5), s.n. INPA 1075 (2.11). Costa, F.R.C. 1051 (2.2), 1055 (2.3), 1056, 1112, 1121, 1177 (2.4), 1049 (2.7). Costa, G.A.G. 134 (2.3), 104 (2.10). Lisbôa, P. 1119 (2.12). Lourenço, A.R.L. 395 (2.3), 358 (2.11). Melo, A. 1021 (1.1), 1033 (1.2), 908, 934, 1021, 1022, 1029, 1030 (1.3), 909, 1032 (1.4), 922, 937, 981 (2.1), 840, 906, $976(2.2), 838,844,910 \mathrm{~A}, 980,987$ (2.3), 928, $1038(2.4), 842,929,949(2.5), 907,924,977$ (2.6), 841, 910B, 982 , 984, 989, 995, 1036, 1042 (2.7), 1041 (2.8), 942, 993 (2.9), 845, 923 (2.10), 843, 979, 986 (2.11), 935 (2.12). Nee, M. 46205 (2.5), 46201 (2.6). Perdiz, R.O. 1019 (2.2), 1044 (2.4), 1408 (2.3), 1428 (2.8). Pereira, P.A. 64 (2.10), 142 (2.8). Pessoa, E. 829 (1.1), 833 , 854 (1.2), 853 (1.3), 852 (1.4), 398 (2.3). Prance, G.T. 22661 (2.5), 9682 (2.6). Santos, S.O. 214 (2.2). 